\title{
Diversity, ecology, and evolution in Phycomyces
}

Lola P. CAMINO ${ }^{a}$, Alexander IDNURM ${ }^{b 1}$, Enrique CERDÁ-OLMEDO $*^{a}$

${ }^{a}$ Departamento de Genética, Universidad de Sevilla, Apartado 1095, E-41080 Sevilla, Spain.

${ }^{\mathrm{b}}$ Division of Cell Biology and Biophysics, School of Biological Sciences, University of Missouri-Kansas City, USA.

${ }^{1}$ Present adress: School of BioSciences, University of Melbourne, Australia,

*Corresponding author: Enrique Cerdá-Olmedo, Tel.: +34-954624107, +34-954557111; fax: $+34-954557104$.

E-mail addresses: lolapcc@us.es (L.P.Camino), alexander.idnurm@unimelb.edu.au (A. Idnurm), eco@us.es (E. Cerdá-Olmedo) 


\begin{abstract}
The fungal genus Phycomyces (Mucoromycotina, Mucorales) has been revised by examining 96 strains, received from established collections or newly isolated from different environments. Morphology, sexuality, DNA sequences, and population structure clearly identify the genus and set it apart from other Mucorales. The size of the spores, the sexual interactions, the sequences of genes $\operatorname{sex} M$ and $\operatorname{sexP}$ that determine sexual identity, and the DNA for ribosomal RNAs validate the species $P$. blakesleeanus and $P$. nitens and the family Phycomycetaceae. Isolates from the same sample of biomass often differ in spore size, sex, DNA sequences, and restriction-length polymorphisms. The widest diversity was found in similar environments in three of the Canary Islands, implying a failure to disperse rapidly over the sea. All strains have apparently functional sexM and sexP genes and all but some strains of $P$. nitens complete the sexual cycle in the laboratory. The genetic diversity of $P$. blakesleeanus strains provides evidence for geographical clustering. Various sequence comparisons, including the newly isolated genes sexM and sexP of P. nitens and Blakeslea trispora, clarify phylogenetic relationships in the Mucorales and recommend the sex genes for the study of speciation.
\end{abstract}

\title{
Keywords
}

Biogeography

Speciation

Phylogeny

Sex allelomorphs

Mucorales

Blakeslea 


\section{Introduction}

Phycomyces is a prominent member of the Mucoromycotina, a vast taxon of Fungi, part of the old Zygomycetes and outside the better known Ascomycota and Basidiomycota. Originally described as an alga (Agardh 1817), hence the genus name, Phycomyces has populated research laboratories for about a century and a half (Carnoy 1870), often pioneering new research fields (Bergman et al. 1969; Cerdá-Olmedo \& Lipson 1987; Cerdá-Olmedo 2001). It remains a fruitful subject for photobiology and other aspects of cell physiology and behaviour, carotene biosynthesis and other aspects of metabolism, and sexuality. This contrasts with the dearth of information on its natural diversity, geographical distribution, ecology, evolution, and relations to other genera of the Order Mucorales, such as Blakeslea, Mucor, and Rhizopus.

Phycomyces is easily recognized by its giant sporangiophores, which grow out of the vegetative mycelium lifting a large sporangium filled with vegetative spores. The mycelia are composed of branched, non-septate, multinucleate hyphae. They belong to either the (+) or the (-) sex, indistinguishable to our sight, but able to interact with each other in a complex series of morphological and biochemical events that culminate in the production of large zygospores. Upon a long dormancy, the zygospore germinates and produces a germsporangiophore, a germsporangium, and germspores, very similar to the akin structures of the vegetative cycle. The germspores, carrying recombinant nuclei, germinate into vegetative mycelia.

Although all natural isolates of Phycomyces look alike, they have been assigned to two species, P. blakesleeanus and P. nitens, on the basis of spore morphology and sexual interactions (Burgeff 1925; Benjamin \& Hesseltine 1959; Zycha et al. 1969). Nearly all laboratory research has been done with $P$. blakesleeanus strains of unknown origin, particularly the standard strain NRRL1555, whose complete genome has been available since 2006 (Joint Genome Institute, US Department of Energy). The genetic analysis of Phycomyces differs notably from that of other organisms, but has led to recombination maps of phenotypic (Orejas et al. 1987) and molecular markers (Chaudhary et al. 2013).

The two sexes of $P$. blakesleeanus depend on specific allelomorphs, DNA sequences with little homology to each other that occupy the same place in linkage group $\mathrm{V}$ of the genome and behave in crosses as single allelic markers (Idnurm et al. 2008). The (+) and (-) allelomorphs contain a gene, $\operatorname{sexP}$ and $\operatorname{sex} M$, respectively, similar to those found in other 
Mucorales: Mucor circinelloides (Lee et al. 2008), Rhizopus oryzae (Gryganskyi et al. 2010), Syzygites megalocarpus (Idnurm 2011a), and M. mucedo (Wetzel et al. 2012). Gene sexM is necessary for mating, but not for vegetative growth in M. circinelloides (Li et al. 2011).

The other Mucorales share the morphological structures that have been described for Phycomyces, with enormous variations in size and shape. The traditional taxonomy, which reached its apex with the book by Zycha et al. (1969), has been revised by DNA sequence comparisons (O’Donnell et al. 2001; Voigt \& Wöstemeyer 2001; Tanabe et al. 2004; White et al. 2006; Walther et al. 2013; Hoffmann et al. 2013), complemented by antibiotic-resistance tests (Vitale et al. 2012). The internal transcribed spacer (ITS) sequences of the genes for rDNA have been recommended by the Consortium for the Barcode of Life to distinguish fungal species (Schoch et al. 2012). The definition of species by the possibility of sexual genetic exchange is of limited use in these fungi, because few complete the sexual cycle in the laboratory, but many initiate unfruitful sexual interactions with distant partners assigned to different genera and families (Blakeslee 1904; Blakeslee \& Cartledge 1927). The intraspecific variation of the Mucorales and its geographical distribution remain largely unexplored (Takó \& Csernetics 2005; Hermet et al. 2012).

Here we consider a broad set of Phycomyces strains, most of them new ones, from multiple view points and look for the relations among them, with their environment, and with other Mucorales. To widen the comparisons, we have obtained the sexual allelomorphs of $P$. nitens and B. trispora.

\section{Materials and Methods}

\subsection{Fungal strains}

The natural strains of the genus Phycomyces (Kunze 1823) used in this work are listed in Table 1, together with the essential data on their origin. Blakeslea trispora (Thaxter 1914) wild-type strains F921 and F986 were obtained from VKM (All-Russian Collection of Microorganisms, Moscow, Russia).

\subsection{Collection and isolation of new strains}

Dung of mice and other small mammals was collected from many locations of the Iberian Peninsula and the Canary Islands. The samples were either picked up from the field or left by 
animals that had been captured with Sherman traps $(240 \times 80 \times 90 \mathrm{~mm})$ in the night and released in the morning. Phycomyces was found in less than one-tenth of the sampled locations.

Occasionally Phycomyces was found growing on various materials (Table 1), often by volunteers. Particularly successful was a call with a description published in the online forum of the University of British Columbia Botanical Gardens.

Samples were incubated at $22^{\circ} \mathrm{C}$ in or on culture medium with sufficient space for the growth of giant sporangiophores and illuminated from above. Single Phycomyces sporangia were crushed between wet tweezer tips and suspended in $1 \mathrm{ml}$ water. In some cases the medium was supplemented with chloramphenicol (34 mg/l) to reduce bacterial contamination. Following another round of single-sporangium purification, up to eight strains were isolated from each original sample. In addition, the original cultures were kept in the dark and examined for the production of zygospores, as an indication of the coexistence of both sexes in the sample.

\subsection{Morphological and physiological characterization}

Standard cultures (Cerdá-Olmedo 1987) were grown from $10^{4}$ spores in the dark on $25-\mathrm{ml}$ minimal agar in standard Petri dishes, $85 \mathrm{~mm}$ in diameter, unless otherwise stated. The standard incubation temperatures were $22^{\circ} \mathrm{C}$ for Phycomyces and $30^{\circ} \mathrm{C}$ for Blakeslea. Colonies for viability tests were obtained on minimal agar adjusted to $\mathrm{pH} 3.3$ with $\mathrm{HCl}$.

For mating, mycelial pieces (about $4 \mathrm{~mm}^{2}$ ) of two strains were set $50 \mathrm{~mm}$ apart on potato dextrose agar (prepared from fresh potatoes) and incubated at $16^{\circ} \mathrm{C}$. Alternatively the agar contained 50 ml/1 "V8 juice" (Campbell Soup Company, Camden, NJ, USA). Zygospores were transferred to damp filter paper in Petri dishes and incubated at $22{ }^{\circ} \mathrm{C}$.

Spore dimensions (20 spores per strain) were measured with a microscope equipped with an eyepiece micrometer or by microphotography. Spore nuclei (at least 100 spores per strain) were counted with a fluorescence microscope after staining with 4',6-diamidino-2phenylindole (DAPI) (Mehta et al. 2003).

Mycelial growth was described by the radial expansion of the mycelia (the average of three colony diameters measured at 24-h intervals) and by the dry mass of lyophilized mycelia from six-days cultures. 
The $\beta$-carotene content of lyophilized mycelia (Govind \& Cerdá-Olmedo 1986) was calculated with the absorption coefficient $(1 \mathrm{~g} / 1,1 \mathrm{~cm}, \lambda=453 \mathrm{~nm})=259.2$.

\subsection{Molecular methods}

The genomic DNA from freeze-dried mycelia was extracted either with GenElute Plant Genomic DNA Miniprep (Sigma-Aldrich, St. Louis, MO, USA) following the manufacturer's instructions (Sambrook \& Russell 2001) or the cetyltrimethyl ammonium bromide protocol (Pitkin et al. 1996).

ITS/5.8S DNA was obtained by PCR with Expand High Fidelity DNA polymerase (Roche Diagnostics, Mannheim, Germany) and primers ITS1 and ITS4 (White et al. 1990) and sequenced at Sistemas Genómicos (Valencia, Spain) by Sanger's dideoxy method.

The restriction-fragment length polymorphisms described by Chaudhary et al. (2013) were tested with the primers listed in Table S1.

The sex allelomorphs of $P$. nitens strains $\mathrm{S} 608$ and $\mathrm{S} 609$ were obtained by a combination of direct and inverse PCR. An internal segment of gene tptA was obtained with primers 5'-AT(C/T)AACAT(C/T)TGCATGTGGTA-3' and 5'-CA(A/G)GT(C/T)CA(C/T)TA(C/T)AC(C/T)CC(C/T)AA-3', designed for the conserved oligopeptides INICMW and QVHYTP of TptA. A segment including parts of genes sexM and $r n h A$ and the intermediate sequence of strain S609 was obtained with primers 5'GACCAAAGAACGCATTCATGC-3' and 5'-GTATTTGCCAGACCAACCATG-3', which are conserved sequences of the respective genes of $P$. blakeleeanus. The polymerase cited above was used for $2 \mathrm{~min}$ at $94^{\circ} \mathrm{C}$, followed by 35 cycles of $30 \mathrm{~s}$ at $94^{\circ}, 30 \mathrm{~s}$ at 52 or $50^{\circ}$, and $1 \mathrm{~min}$ at $72^{\circ}$, and a final extension of $7 \mathrm{~min}$ at $72^{\circ}$.

Circularized segments of genomic DNA were obtained by digestion in parallel experiments with 12 restriction enzymes (BamHI, BglII, ClaI, EcoRI, HindIII, KpnI, NcoI, PstI, SalI, SpeI, XbaI and XhoI) and self-ligation with T4 DNA ligase (New England BioLabs Ipswich, MA, USA). The ligation products were subjected to inverse PCR with primers from sequences of the $P$. nitens genes $t p t A$, $r n h A$ and $\operatorname{sex} M$ by using ExTaq DNA polymerase (Takara Bio, Shiga, Japan) for $2 \mathrm{~min}$ at $94^{\circ} \mathrm{C}, 32$ cycles of $15 \mathrm{~s}$ at $94^{\circ}, 20 \mathrm{~s}$ at 52 to $55^{\circ}$ and 3 $\min$ at $72^{\circ}$, and a final extension of $5 \mathrm{~min}$ at $72^{\circ}$. Sequencing the DNA products provided new primers for additional rounds of inverse PCR. The final sequences were assembled with the Sequencher software (Gene Codes, Ann Arbor, MI, USA). 
The same inverse PCR procedure was used for the sex allelomorphs of B. trispora, strains F921 and F986, starting from a fragment of gene $r n h A$ of strain F921, which was obtained as described for Syzygites (Idnurm 2011a).

\subsection{Bioinformatics}

BLAST programs were used to search genome databases. DNA and protein sequences were aligned with ClustalW (Thompson et al. 1994), but those used to obtain cladograms were obtained with Muscle (Edgar 2004), and improved by eye. BLASTn (Altschul et al. 1990) helped localize putative genes, domains, and motifs DNA Strider 1.4 (Marck 1988) produced putative protein sequences, which were inspected by eye. Table S2 has the accession numbers of DNA and protein sequences taken from GenBank and those generated in this work

Maximum-likelihood cladograms of nucleotide sequences were obtained with Mega5.2.2 (Tamura et al. 2011). The bootstrap consensus trees were inferred from 1000 replicates.

Statistical analyses were performed in R (R Core Team 2013). A Jaccard distance matrix of dissimilarity of 56 strains of P. blakesleeanus was calculated from the presence or absence of 27 restriction-fragment length markers in their genomes and subjected to nonmetric multidimensional scaling (NMDS) analysis. Whether the missing data were included or not in the analyses made very little difference (Mantel $r=0.986, p<0.001$ ). Computations were conducted using the R 'vegan' package (Oksanen et al. 2012) and graphed with the 'ggplot2' package (Wickham 2009). The data for different geographical groups of strains in the Jaccard matrix were subjected to analysis of molecular variance (AMOVA; Excoffier et al. 1992) and the significance of their differences was calculated after 5000 permutations. The metric distances required by AMOVA were obtained by setting 'distance method' to 'euclidean' in the 'amova' function of the 'pegas' package (Paradis 2010).

\section{Results}

\subsection{Old and new Phycomyces strains}

We considered 99 Phycomyces strains (Table 1), including 45 received from various collections, 21 new strains from Spain, and 33 new strains from the USA. The new strains 
were isolated from materials provided by external volunteers, except 12 that were isolated by members of the Spanish laboratory. The new strains were found growing on various substrates, except six that were grown from dung of small animals collected in Andalusia and the Canaries and incubated in the laboratory. The strains isolated from the same biomass were considered a local population; thus, a single sample from Houston, Texas, USA, provided 6 strains that could be distinguished by their sex and other alleles.

All Phycomyces strains could be classified unambiguously as $P$. nitens or $P$. blakesleeanus by traditional criteria (Burgeff 1925; Benjamin \& Hesseltine 1959; Zycha et al. 1969). Both are cosmopolitan species (Fig. 1), although all the new strains from Spain were $P$. nitens, and all but two of the new strains from the USA were P. blakesleeanus. Our collection is unbiased, because collectors could not distinguish the species by visual inspection. Both species were found in a sample of seeds from an animal feeder in Howell, Michigan, USA, but they could have been brought together accidentally by man or animals.

Both sexes of $P$. nitens were found in a sample from the Higueral cave in Andalusia, Spain (Baena et al. 2012) and both sexes of P. blakesleeanus were found in three samples, from Texas, Tennessee, and Virginia. The new Phycomyces strains were accompanied in the original biomass by many other microorganisms, including various species of Mucor and Rhizopus.

\subsection{Spore size and number of nuclei}

The spores of $P$. blakesleeanus were smaller, rounder, and more uniform than those of $P$. nitens. The average length of the spores taken from a single sporangium was sufficient to distinguish the species, but a single spore was not, because of some overlap in the spores of extreme size. The length $v s$. eccentricity plot (Fig. 2) offered a clearer distinction than the length $v s$. width plot.

The spore size did not correlate with the geographical origin. The largest spores were those of $P$. nitens strains isolated from Japan, England (Avon County), Germany, and La Palma (one of the Canary Islands). The smallest $P$. nitens spores were often found in the vicinity of the largest, in England (Surrey County) and La Gomera (another Canary island).

The average number of nuclei per spore, measured in 18 strains, was another excellent criterion for species determination, being $>8$ in P. nitens and $<4$ in P. blakesleeanus (Fig. 2 and Table S3). The number of nuclei per spore in each strain varied widely, along with the spore size, and more so in the former than in the latter. Thus, the variation coefficient of the 
distribution of nuclei per spore was 0.34 in P. nitens S644 and 0.20 in P. blakesleeanus NRRL1555.

The extreme values were the few uninucleate spores found in some P. blakesleeanus strains and the spores with over 30 nuclei seen in some $P$. nitens strains. A spore with more than 8 nuclei should be assigned to $P$. nitens, but lower values would be ambiguous. The standard strain NRRL1555 is noteworthy for the low number of nuclei and the low eccentricity of its spores.

\subsection{Mycelial growth and color}

At a glance, the growth of the strains was rather uniform, and it was measured in only a few strains from different locations. The temperature preferences for growth did not match the geographical origins of the strains tested (Fig. 3). In terms of dry mass, all the strains grew at $30{ }^{\circ} \mathrm{C}$, but not better than at lower temperatures; strains from the Canary Islands grew worst. About half of strains were mesophilic (they preferred $22^{\circ} \mathrm{C}$ to $16^{\circ} \mathrm{C}$ ) and the others relatively psychrophilic (the other way around). At $4{ }^{\circ} \mathrm{C}$, strains from the Iberian Peninsula, Canary Islands and Canada ( $P$. nitens S257, S609, S642, S645, and UBC39) produced thick mycelia that took five days to reach $5 \mathrm{~mm}$ in diameter; the spores of the other strains tested either did not germinate or produced germlings only.

All strains expanded faster at $22^{\circ} \mathrm{C}$ than at $16^{\circ} \mathrm{C}$. The maximal daily expansion at $22{ }^{\circ} \mathrm{C}$ was close to $17 \mathrm{~mm} /$ day in all strains, with a variation coefficient of only 0.10 , the lowest found in our quantitative measurements. The dry biomass per colony surface was also similar for all strains, $43 \mathrm{~g} / \mathrm{m}^{2}$. P. nitens $\mathrm{S} 642$ was noted by its rapid expansion and abundant sporulation from its thin and largely submerged mycelium.

A high $\beta$-carotene content would offer an attractive start for the breeding of industrial strains. We paid particular attention to our new isolates of $P$. nitens. Some of them had about $90 \mu \mathrm{g} \beta$-carotene/g dry mass four days after spore germination, and were therefore similar to NRRL1555, the standard strain of P. blakesleeanus. Many exceeded this value and P. nitens S642 more than doubled it (Table S4).

\subsection{DNA sequences for ribosomal RNA in Phycomyces}

Tandem DNA sequence repeats (Fig. 4), located in linkage group VII, code for the four rRNAs (18S, 5.8S, 28S, and 5S) and contain the internal transcribed spacers (ITS1 and ITS2) and the intergenic spacers (IGS1 and IGS2). The structure in Fig. 4 was assembled from 
sequences located in the P. blakesleeanus genome. IGS2 varies in sequence and in length (4723, 6096, $4704 \mathrm{bp}$ ), but the other seven segments of the structure have the same length (7051 bp) and nearly the same sequence. The 5S rRNA and the other rRNAs are coded in opposite DNA strands.

The DNA for the 5.8S rRNA was identical in the ninety-three strains of $P$. nitens and $P$. blakesleeanus that were sequenced. The ITS/5.8S sequences, composed of ITS1 (195 bp), 5.8S (157 bp), and ITS2 (262 bp), fell in two clusters that corresponded to the biological species. Strains from different species varied in 14 to $15 \%$ of the $614 \mathrm{bp}$ and those from the same species varied much less (Fig. 5). In P. blakesleeanus 50 strains, including NRRL1555, shared the ITS/5.8S sequence; three other strains diverged in one to five nucleotides. In $P$. nitens 38 strains shared the ITS/5.8S sequence or differed from it in only one nucleotide. The largest divergence was that of strain NRRL2444, from England, which differed from the predominant sequence in 14 nucleotides.

The multicopy ITS/5.8S sequences were uniform in most strains, with a few cases of heterogeneity detected in a single nucleotide of the ITS1 sequence. S609 and eight other $P$. nitens strains had A/G in position 17 and P. blakesleeanus CBS188.27 had A/C in position 15.

\subsection{Intraspecific diversity in P. blakesleeanus}

The strains of $P$. blakesleeanus were tested for twenty-seven single nucleotide polymorphisms (SNP). Strains NRRL1555 and UBC21, the only wild types whose genomes have been sequenced, differ in these markers localized throughout the genome (Chaudhary et al. 2013). The same analyses could not be repeated with $P$. nitens because of insufficient conservation of the DNA sequences.

Isolates with identical alleles were discarded from subsequent analysis if they had the same sex and came from the same site (Table 1). Strains CBS189.27 and CBS282.35, suspected to be identical (Ootaki \& Miyazaki 1993), are in fact different.

A simple analysis of the alleles that each strain shares with UBC21 (Table S6) unveils the close relationships within each local population and the wide spread of the strains from North America.

The powerful NMDS analysis represents the relationships of the genome sequences as a two-dimensional graph of the strains (Fig. 6). Local populations form tight clusters. The strains from Europe, Eastern North America, and Western North America form significantly 
different groups according to the analysis of molecular variance $\left(\sigma^{2}=0.05, p<0.001\right)$.

Some strains were aberrant in morphology and in conduct. Two European strains in the lower left are natural piloboloides mutants, with sporangiophores bulged just below the sporangium (Burgeff 1915, 1928; Benjamin \& Hesseltine 1959; Yoshida et al. 1980; Ootaki $\&$ Tsuru 1993). UBC1, a strain from British Columbia that groups with other Western North American strains, may be called nanus because of its very short sporangiophores and its incomplete sexual interaction (Burgeff 1928).

\subsection{Sexual behavior of Phycomyces}

All the $P$. blakesleeanus strains interacted sexually under the laboratory conditions and could be classified as (+) or (-). Along the line of contact between mycelia of opposite sex appeared a bright yellow band with modified hyphae ("sexual tissue") and abundant, fertile zygospores. Only UBC1 failed to produce normal zygospores.

Under the same conditions most of the $P$. nitens strains reacted weakly, with only a slight accentuation of the yellow color and few or no zygospores; sixteen strains could not be clearly assigned to one of the sexes, except by analysis of the sex genes. The (+) strains S256 and S608 and the (-) strains S605, S606, S609, and S642 completed the sexual cycle. After a dormancy period similar to that of P. blakesleeanus, most of their zygospores germinated to produce viable germspores (Fig. S1).

Crosses of the P. blakesleeanus strains NRRL1555 and UBC21 with many of the new strains of $P$. nitens produced the bright yellow band and "sexual tissue", but no mature zygospores.

\subsection{Sex allelomorphs of $\mathrm{P}$. nitens and $\mathrm{B}$. trispora}

The sex allelomorphs of $P$. blakesleeanus and M. circinelloides are flanked by genes tptA, for a putative triose phosphate transporter, and $r n h A$, for a putative RNA helicase, and contain each a gene, sexM or $\operatorname{sexP}$ (Idnurm et al. 2008; Lee et al. 2008). The sequences of these genes were used to obtain the sex allelomorphs of $P$. nitens and B. trispora (Fig. 7). No sequences related to the sex allelomorphs were found around gene tptA of $P$. nitens.

The sex allelomorphs of B. trispora are the shortest known in the Mucorales, with 1145 and $993 \mathrm{bp}$ for (+) and (-), respectively. The (-) allelomorph of P. nitens, with $2084 \mathrm{bp}$, is the second longest, after that of P. blakesleeanus. The (+) allelomorph, with $3716 \mathrm{bp}$, is the third longest, after those of $R$. oryzae and P. blakesleeanus. 
The sex genes proper are short and very similar in length: $958 \pm 24$ bp for $\operatorname{sex} P$ and $668 \pm 69 \mathrm{bp}$ for $\operatorname{sexM}$ (mean and standard deviation for the species shown in Fig. 7). They are all transcribed in the same direction as gene $r n h A$, with the exception of $\operatorname{sexP}$ of Phycomyces; thus, in this genus the sex genes are inverted with respect to each other.

The $\operatorname{sex} P$ gene of $P$. nitens is preceded by the sequence GATCgtccAcCCAAT, a transcription-factor binding motif (Jones et al. 1987). The capitalized nucleotides are conserved in P. blakesleeanus, M. mucedo, M. circinelloides, and R. oryzae (Wetzel et al. 2012). This motif was not found in B. trispora.

Of the $P$. nitens strains whose sex had to be determined by sequencing, nine had gene sexP and seven had gene $\operatorname{sex} M$, all identical to those of the sexually active strains $\mathrm{S} 609$ and S608. The only exception was strain S607, whose predicted SexP protein sequence differs from the others in eight amino acids that do not affect the HMG domain. The 573-bp noncoding sequence between sexM and $r n h A$ is highly conserved in the eight strains of $P$. nitens that were sequenced, with variations in less than $0.1 \%$ of the nucleotides. This sequence presumably contains the $r n h A$ promoter.

\section{Discussion}

\subsection{Species of Phycomyces}

The species $P$. nitens and $P$. blakesleeanus are clearly set apart by spore morphology, number of nuclei per spore, sexual behavior, sex loci, ITS/5.8S sequences, and the failure to amplify $P$. nitens DNA with PCR primers from P. blakesleeanus. The length and width of a few spores suffice to assign isolates to one or the other species.

We do not know the selective forces that separated the two species of Phycomyces and maintain each as a tight cluster of strains. So tight, for example, that gene sex $M$ has the same sequence in all the strains of $P$. nitens that we have analyzed, irrespective of their geographical origin all over the Earth. No strains, old or new, justify the recognition of new species.

NRRL1555, the standard and most used strain of P. blakesleeanus, resembles the majority of the strains of this species in all respects, but for its few nuclei per spore, a convenient trait for mutational analysis. Strain NRRL2444, from England, used in sexuality tests (Benjamin \& Hesseltine 1959), is the most outlying, and thus the least representative, of all the strains of $P$. nitens, as seen in their spores and their ITS $/ 5.8 \mathrm{~S}$ sequences. 


\subsection{Geographical distribution and ecology}

Phycomyces has been found in the Old and the New Worlds and in Oceania at latitudes ranging from Finland and Canada to the tropics. Nearly all the strains look the same and the small differences in growth demands are unrelated to their geographical origins. Growth is thus likely to be limited to seasons and other circumstances that meet the demands in each geographical location, with the adverse intervals straddled by the durability of vegetative spores and zygospores.

Phycomyces requires a relatively high humidity. We sampled many environments in the Canary Islands, from deserts to wet forests, from coasts to high mountains. All the strains were found at around one km over sea level in humid, often foggy laurisilva.

The natural microenvironments of Phycomyces are relatively uniform. Eight of the Spanish strains were found in three deep limestone caves and most of the others came from volcanic and karstic terrains where caves abound. Phycomyces does not shun human proximity; many of the samples sent by volunteers were picked up near, or even inside houses.

Our most diverse strains were collected less than $150 \mathrm{~km}$ from each other in very similar environments of three Canary Islands. This is an extension to the fungal world of many observations of island biology, for example, on the finches of the Galápagos by C. Darwin and on the Gallotia lizards of the Canaries (Cox et al. 2010). The divergence of island strains indicates that Phycomyces does not disseminate rapidly to large distances. Nor was this expected, because the vegetative spores and the zygospores are hardly dispersible in air or water and do not seem to associate with birds; on the contrary, they are sticky and easily carried by mammals.

\subsection{Local populations}

Knowledge of the diversity of local populations, scarce in the non-Dikarya Fungi, is needed to understand ecology and evolution and to manage emerging problems, such as the worldwide decline of amphibians caused by Batrachochytrium dendrobatidis (Rosenblum et al. 2013) and the outbreak of mucormycosis caused by Apophysomyces trapeziformis among victims of a very localized tornado (Weddle et al. 2012). Moreover, screening the natural diversity should be the first step for practical applications. 
Our local populations were genetically heterogeneous, as shown in P. blakesleeanus by restriction-length polymorphisms and in $P$. nitens by differences in sex, spores, and DNA sequences. Notable is the case of the three strains found in a single biomass sample from the Higueral cave, which differed in sex, sexual vigor, ten nucleotides of the ITS/5.8S sequences, and fifteen nucleotides of the $\operatorname{sex} P$ gene.

The quantitative analysis of restriction-length differences in P. blakesleeanus allowed us to distinguish local populations and to group them in larger geographical areas (Fig. 6). This analysis was limited to differences between the reference strains NRRL1555 and UBC21, for which the needed sequence information was available. Unfortunately, the origin of these is not documented.

Strain UBC21 comes from the collection of R. J. Bandoni, University of British Columbia, and NRRL1555 may well come from A. F. Blakeslee (Benjamin \& Hesseltine 1959), who worked mostly at Cold Spring Harbor, near New York. Our results are understandable if both strains are autochthonous American. NRRL1555 is likely to come from southeastern USA. If this is the case, our analysis forces the strains from Europe and Eastern Asia to be placed between the reference strains, even if differences in other restriction sites would have placed them far away from both. Our results make it unlikely that NRRL1555 and UBC21 come from Europe and even more so that they come from different continents.

\subsection{Sex determination}

The SexP and SexM proteins of the Mucorales (Fig. S2) are putative sex-specific transcription factors, since they contain a sequence similar to the HMG domain found in genes responsible for sex determination in many organisms (Idnurm et al. 2008; Czaja et al. 2014). The DNA-binding amino acids in HMG have been identified in the tridimensional structures of proteins from Saccharomyces cerevisiae (Bell et al. 1977) and Mus musculus (Love et al. 1995). The HMG domains of the sex genes of the Mucorales evolve under general constraints, evidenced by the absolute conservation of seven amino acids, and sexspecific constraints, evidenced by the conservation of twelve amino acids in SexP and one in SexM. The generally-constrained amino acids and many sex-constrained ones coincide with or are contiguous to the DNA-binding amino acids.

Genes $\operatorname{sexP}$ and $\operatorname{sex} M$ are related to each other and have diverged to the same extent in different Mucorales, with $39.1 \pm 1.4 \%$ coincident nucleotides (mean and standard deviation 
for the four species represented in Fig. 7). This suggests that these organisms have arrived to a similar equilibrium between the opposite selective pressures to maintain the common function as transcription factors and to carry out sex-specific functions.

The transcript level of gene sexM in M. mucedo increases in mated cultures of strains of opposite sex and upon exposure to a mixture of trisporoids; the same occurs to a lesser extent with $\operatorname{sexP}$ (Wetzel et al. 2012). Sexual development is accompanied by modified levels of the transcripts of several hundred genes in mated cultures (Kuzina et al. 2008).

The high conservation of the sex and species-specific segments on both sides of $\operatorname{sexP}$ in B. trispora and between sexM and $r n h A$ in $P$. nitens makes them useless for strain identification and implies a selective pressure. This comes, at least in part, from the regulation of $r n h A, \operatorname{tpt} A$, $\operatorname{sex} M$, and $\operatorname{sex} P$, whose promoters are presumably in those regions, and in fact a target for transcription factors is present upstream of sexP in Phycomyces and other Mucorales.

The sex allelomorphs have four anti-recombination features: the sex genes are small, their sequences are only partially homologous, they are surrounded by unique sex-specific sequences, and, in some cases, they run in opposite direction. These features are particularly strong in Phycomyces and all the tested strains of this fungus can be assigned unequivocally to the (+) or the (-) sex and have a complete and apparently functional $\operatorname{sex} P$ or $\operatorname{sex} M$ gene. The situation in Blakeslea appears more prone to internal recombination and it would be worth knowing the frequency in this fungus of natural strains with a dysfunctional, recombinant sex gene.

In Phycomyces we found no indications of intraspecific barriers to sexual reproduction, such as the vegetative incompatibilities common in many fungi and plants.

\section{5 rRNA}

There are three types of tandem DNA repeats for rRNA in the fungi, each widely distributed. In one of the types, found in species of all major fungal groups, the $5 \mathrm{~S}$ gene is not part of the tandem repeats that include the other rRNA genes (Bergeron \& Drouin 2008). When it is part of the repeat, it can be transcribed in the opposite direction to the other genes, as it occurs in the Mucorales P. blakesleeanus (Fig. 4), M. racemosus (Cihlar \& Sypherd 1980), M. (now Rhizomucor) miehei (Maicas et al. 2000), and Absidia glauca, and in many other fungi, including Saccharomyces cerevisiae (Aarstad \& Oyen 1975) and most of the Ascomycota. In 
R. oryzae and in most of the Basidiomycota the $5 \mathrm{~S}$ gene is transcribed in the same direction as the other genes.

A low level of sequence heterogeneity within each strain, as found in our ITS/5.8S sequences of Phycomyces, is probably common in the Fungi. Other examples were found in the P. blakesleanus genome sequence, in R. microsporus (Woo et al. 2010), and outside the Mucorales (Ganley \& Kobayashi 2007).

\subsection{Cladograms of Mucorales}

For comparisons with other Mucorales we chose strains NRRL1555 and UBC21 of $P$. blakesleeanus and strains S608 and S609 of P. nitens because they carry the most common sequence variants that we have studied. The cladograms of these sequences (Fig. 8) coincide in topology and overall size, although the sequences have very different functions and are presumably subject to very different selection pressures. The seven species are repeatedly distributed in three groups: Phycomyces, Blakeslea-Mucor, and Rhizopus-Syzygites. The detection of separate sexM and sexP genes in all the Mucorales under study indicates that these organisms diverged after the two genes had diverged in a common ancestor.

The internodal distances indicate variations in the divergence rate of the sequences. The ITS/5.8S sequences of Blakeslea and Mucor are tightly clustered, suggesting that these genera of different families form a young clade. Their sex genes have evolved very rapidly. Even more divergent are the non-transcribed sequences in the sexual allelomorphs, where the promoters should be located. The sexual allelomorphs would be relevant for speciation (Idnurm 2011b) by making the function and the regulation of the sex genes dependent on the external environment and on the molecular composition of the cells. The barriers to genetic exchange would facilitate the rapid evolution of the traits subject to weak selective pressures, including the morphology used to define genera and species. We recommend comparisons of the sex genes and the whole allelomorphs to study the genera that are poorly resolved by other sequences (Hoffmann et al. 2013; Walther et al. 2013).

The sex genes of the R. oryzae and S. megalocarpus (Fig. 8) have diverged slower than their ITS/5.8S sequences, a surprising observation since the first is heterothallic and the second homothallic. In the cladogram of the Rhizopodaceae, homothallic species of Syzygites and Rhizopus are interspersed with heterothallic species of Rhizopus and other genera (Walter et al. 2013). The presence of both $\operatorname{sex} P$ and $\operatorname{sex} M$ in homothallic species may be due to asymmetric recombination or translocation during the sexual cycle (Idnurm 2011a). Single 
colonies of intersexual partial diploids (Mehta \& Cerdá-Olmedo 2001) and intersexual heterokaryons (Murillo et al. 1978) of Phycomyces, which carry both sex genes, exhibit partial sexual interactions and novel structures, the pseudophores, but are not homothallic. The production of zygospores would require additional mutations, but these should not be very numerous, given the interspersion of both life styles in the Rhizopodaceae.

According to the ITS/5.8S sequences (Fig. S3), the distance between the two species of Phycomyces, which look nearly identical, is larger than the distances between the genera Blakeslea, Choanephora, and Poitrasia of the family Choanephoraceae. The morphology of Phycomyces is presumably maintained by its adaptation to a rather constant environment, found all over the world.

\subsection{Life cycles of the Mucorales}

The results on the diversity of local populations and on sex gene sequences suggest that natural populations of Phycomyces are much more active sexually than usually assumed by laboratory researchers. Active sexuality explains the rarity of heterokaryosis in natural isolates. The sexual cycle favors homokaryosis because the nuclei in each germspore derive normally from a single haploid genome produced by recombination of a single pair of parental nuclei (Cerdá-Olmedo 1975). On the contrary, the multinucleate mycelia and spores of the vegetative cycle facilitate the maintainance and the transmision of spontaneous mutations (Heisenberg \& Cerdá-Olmedo 1968).

There are clear parallelisms between the life cycles of Phycomyces and other Mucorales and Homo sapiens. The vast majority of the genome replications occur in the respective vegetative cycles, leading to the formation of large colonies or individuals, where most of the life processes take place. The sexual cycle plays an essential role in population structure, but is spaced in time by powerful clocks that in one case keep the zygospores dormant for months and in the other delay sexual maturity for years. The genetic diversity introduced during the vegetative cycle by mutations, even deleterious ones, is largely kept under cover by multinucleatedness in one case and diploidy in the other. Sex purifies most of this variation in both cases. At the same time, the sexual processes introduce new variation in the form of recombinants and new mutations.

The life cycles of the Mucorales are more flexible than ours, as they allow unlimited vegetative growth and clonal subcultures, and are more strict in the elimination of deleterious 
mutations, which do not survive the haploidy of the germspores, but are maintained by our diploidy.

\section{Acknowledgements}

We appreciate the help of Prof. Carlos M. Herrera with numerical analysis. Dr. Atsushi Miyazaki, Dr. James Swezey and Dr. Seung-Beom Hong provided Phycomyces strains from culture collections and Juan Pino Palma, Prof. Cesáreo Sáiz, and the volunteers in Table 1 collected Phycomyces samples (Table 1). We thank Prof. Gabriel Gutiérrez, Dr. Silvia Polaino, Dr. Viplendra Shakya and Marta Pérez-Alcántara for their assistance. This research was supported by Fundación José Miguel Villar Mir, Junta de Andalucía (P08-CVI-03901), the Spanish Government (BIO2012-38520 and BIO2012-39716), Australian Research Council and the United States National Science Foundation (grant MCB-0920581).

\section{REFERENCES}

Aarstad K, Oyen TB, 1975. On the distribution of 5S RNA cistrons on the genome of Saccharomyces cerevisiae. FEBS Letters 51: 227-231.

Agardh CA, 1817. Synopsis algarum Scandinaviae, adjecta dispositione universali algarum. Ex. Officina Berlingiana, Lund.

Altschul SF, Gish W, Miller W, Myers EW, Lipman DJ, 1990 Basic local alignment search tool. Journal of Molecular Biology 215: 403-410.

Baena J, Morgado A, Lozano JA, Torres C, Alcalá A, Bermúdez R, Bermúdez F, Ruíz-Ruano F, 2012. Titans in the Motilla complex. The upper pleistocene sequence at cave of El Higueral-Guardia in the western Betic. Menga 3: 107-117.

Bejarano ER, Parra F, Murillo FJ, Cerdá-Olmedo E, 1988. End-product regulation of carotenogenesis in Phycomyces. Archives of Microbiology 150: 209-214. 
Bell GI, De Gennaro LJ, Gelfand DH, Bishop RJ, Valenzuela P, Rutter WJ, 1977. Ribosomal RNA genes of Saccharomyces cerevisiae. I. Physical map of the repeating unit and location of the regions coding for $5 \mathrm{~S}, 5.8 \mathrm{~S}, 18 \mathrm{~S}$, and $25 \mathrm{~S}$ ribosomal RNAs. Journal of Biological Chemistry 252: 8118-8125.

Benjamin CR, Hesseltine CW, 1959. Studies on the genus Phycomyces. Mycology 51:751-771.

Bergeron J, Drouin G, 2008. The evolution of 5S ribosomal RNA genes linked to the rDNA units of fungal species. Current Genetics 54: 123-131.

Bergman K, Burke PV, Cerdá-Olmedo E, David CN, Delbrück M, Foster KW, Goodell EW, Heisenberg M, et al., 1969. Phycomyces. Bacteriological Reviews 33: 99-157.

Blakeslee AF, 1904. Sexual reproduction in the Mucorineae. Proceedings of the American Academy of Arts and Sciences 40: 205-319.

Blakeslee AF, Cartledge J, 1927. Sexual dimorphism in Mucorales. II. Interspecific reactions. Botanical Gazette 84: 51-57.

Burgeff H, 1915 Untersuchungen über Variabilität, Sexualität und Erblichkeit bei Phycomyces nitens Kunze II. Flora 108: 353-448.

Burgeff H, 1925. Über Arten und Artkreuzung in der Gattung Phycomyces Kunze. Flora 118: $40-46$.

Burgeff H, 1928. Variabilität, Vererbung und Mutation bei Phycomyces blakesleeanus Bgff. Zeitschrift für Vererbungslehre 49: 26-94.

Carnoy JB, 1870. Recherches anatomiques et physiologiques sur les champignons. Bulletin de la Société Royale de Botanique de Belgique 9: 157-321.

Cerdá-Olmedo E, 1975. The genetics of Phycomyces blakesleeanus. Genetical Research 25: $285-296$.

Cerdá-Olmedo E, Lipson ED, 1987. Phycomyces. Cold Spring Harbor Laboratory Press, New York. 
Cerdá-Olmedo E, 1987. Standard growth conditions and variations. In Cerdá-Olmedo E, Lipson ED (eds), Phycomyces. Cold Spring Harbor Laboratory Press, New York, pp 337-339.

Cerdá- Olmedo E, 2001. Phycomyces and the biology of light and color. FEMS Microbiology Reviews 25: 503-512.

Chaudhary S, Polaino S, Shakya VPS, Idnurm A, 2013. A new genetic linkage map of the zygomycete fungus Phycomyces blakesleeanus. PLoS One 8:e58931. doi:10.1371/journal.pone.0058931.

Cihlar RL, Sypherd PS, 1980. The organization of the ribosomal RNA genes in the fungus Mucor racemosus. Nucleic Acids Research 8: 793-804.

Cox SC, Carranza S, Brown RP, 2010. Divergence times and colonization of the Canary Islands by Gallotia lizards. Molecular Phylogenetics and Evolution 56: 747-757.

Czaja W, Miller KY, Skinner MK, Miller BL, 2014. Structural and functional conservation of fungal MatA and human SRY sex-determining proteins. Nature Communications 5: 5434.

Edgar RC, 2004. MUSCLE: multiple sequence alignment with high accuracy and high throughput. Nucleic Acids Research 32: 1792-1797.

Excoffier L, Smouse, PR, Quattro JM, 1992. Analysis of molecular variance inferred from metric distances among DNA haplotypes: application to human mitochondrial DNA restriction data. Genetics 131: 479-491.

Ganley AR, Kobayashi T, 2007. Highly efficient concerted evolution in the ribosomal DNA repeats: total rDNA repeat variation revealed by whole-genome shotgun sequence data. Genome Research 17: 184-191.

Govind N, Cerdá-Olmedo E, 1986. Sexual activation of carotenogenesis in Phycomyces blakesleeanus. Journal of General Microbiology 132: 2775-2780. 
Gryganskyi AP, Lee SC, Litvintseva AP, Smith ME, Bonito G, Porter TM, Anishchenko IM, Heitman J, Vilgalys R, 2010. Structure, function, and phylogeny of the mating locus in the Rhizopus oryzae complex. PLoS One 5:e15273. doi:10.1371/journal.pone.0015273.

Heisenberg M, Cerdá-Olmedo E, 1968. Segregation of heterokaryons in the asexual cycle of Phycomyces. Molecular and General Genetics 102: 187-195.

Hermet A, Meheust D, Mounier J, Barbier G, Jany JL, 2012. Molecular systematics in the genus Mucor with special regards to species encountered in cheese. Fungal Biology 116: $692-705$.

Hoffmann K, Pawlowska J, Walther G, Wrzosek M, de Hoog GS, Benny GL, Kirk PM, Voigt K , 2013. The family structure of the Mucorales: a synoptic revision based on comprehensive multigene-genealogies. Persoonia 30: 57-76.

Hong SB, Kim DH, Lee M, Hong SB, Kim DH, Lee M, Baek SY, Kwon SW, Houbraken J, Samson RA, 2012. Zygomycota associated with traditional meju, a fermented soybean starting material for soy sauce and soybean paste. Journal of Microbiology 50: 386393.

Idnurm A, Walton FJ, Floyd A, Heitman J, 2008. Identification of the sex genes in an early diverged fungus. Nature 451: 193-196.

Idnurm A, 2011a. Sex determination in the first-described sexual fungus. Eukaryotic Cell 10: $1485-1491$.

Idnurm A, 2011b. Sex and speciation: the paradox that non-recombining DNA promotes recombination. Fungal Biology Reviews 25: 121-127.

Jones KA, Kadonaga JT, Rosenfeld PJ, Kelly TJ, Tjian R, 1987. A cellular DNA-binding protein that activates eukaryotic transcription and DNA replication. Cell 48: 79-89.

Kunze G, 1823. Phycomyces. Mykologische Hefte 2: 113-114. 
Kuzina V, Ramírez-Medina H, Visser H van Ooyen AJ, Cerdá-Olmedo E, van den Berg JA, 2008. Genes involved in carotene synthesis and mating in Blakeslea trispora. Current Genetics 54: 143-152.

van Laere AJ, 1983. Stimulation of phosphofructokinase from Phycomyces blakesleeanus and some other fungi by micromolar concentrations of fructose 2, 6-biphosphate. Journal of General Microbiology 129: 3281-3285.

Lee SC, Corradi N, Byrnes EJ, Torres-Martinez S, Dietrich FS, Keeling PJ, Heitman J, 2008. Microsporidia evolved from ancestral sexual fungi. Current Biology 18: 1675-1679.

Li CH, Cervantes M, Springer DJ, Boekhout T, Ruiz-Vazquez RM, Torres-Martinez SR, Heitman J, Lee SC, 2011. Sporangiospore size dimorphism is linked to virulence of Mucor circinelloides. PLoS Pathogens 7:e1002086, doi:10.1371/journal.ppat.1002086.

Love JJ, Li X, Case DA, Giese K, Grosschedl R,Wright PE, 1995. Structural basis for DNA bending by the architectural transcription factor LEF-1. Nature 376: 791-795.

Maicas S, Adam AC, Polaina J, 2000. The ribosomal DNA of the Zygomycete Mucor miehei. Current Genetics 37: 412-419.

Marck C, 1988. 'DNA Strider': a 'C' program for the fast analysis of DNA and protein sequences on the Apple Macintosh family of computers. Nucleic Acids Research 16: 1829-1836.

Mehta BJ, Cerdá-Olmedo E, 2001. Intersexual partial diploids of Phycomyces. Genetics 158: 635-641.

Mehta BJ, Obraztsova IN, Cerdá-Olmedo E, 2003. Mutants and intersexual heterokaryons of Blakeslea trispora for production of $\beta$-carotene and lycopene. Applied and Environmental Microbiology 69: 4043-4048.

Murillo FJ, Calderón IL, López-Díaz I, Cerdá-Olmedo E, 1978. Carotene-superproducing strains of Phycomyces. Applied and Environmental Microbiology 36: 639-642. 
O’Donnell K, Lutzoni F, Ward TJ, Benny GL, 2001. Evolutionary relationships among mucoralean fungi, Zygomycota): evidence for family polyphyly on a large scale. Mycologia 93: 286-296.

Oksanen J, Blanchet FG, Kindt R, Legendre, Minchin PR, O'Hara RB, Simpson GL, Solymos P, Stevens MHH, Wagner H, 2012. vegan: community ecology package R package version 2.0-1.

Ootaki T, Miyazaki A, 1993. Genetic nomenclature and strain catalogue of Phycomyces. Tohoku University, Sendai.

Ootaki T, Tsuru T, 1993. Diphasic negative phototropism of sporangiophores of the piloboloid mutant of Phycomyces blakesleeanus. Experimental Mycology 17: 103 108.

Orejas M, Peláez MI, Álvarez MI, Eslava AP, 1987. A genetic map of Phycomyces blakesleeanus. Molecular and General Genetics 210: 69-76.

Paradis E, 2010. pegas: an R package for population genetics with an integrated-modular approach. Bioinformatics 26: 419-420.

Pitkin JW, Panaccione DG, Walton JD, 1996. A putative cyclic peptide efflux pump encoded by the TOXA gene of the plant-pathogenic fungus Cochliobolus carbonum. Microbiology 142: 1557-1565.

R Core Team, 2013. R: a language and environment for statistical computing. R Foundation for Statistical Computing, Vienna.

Rosenblum EB, James TY, Zamudio, KR, Poorten T J, Ilut D, Rodriguez D, Eastman, J M, Richards-Hrdlicka K, et al., 2013. Complex history of the amphibian-killing chytrid fungus revealed with genome resequencing data. Proceedings of the National Academy of Sciences USA 110: 9385-9390.

Sambrook J, Russell DW, 2001. Molecular Cloning. A Laboratory Manual. Cold Spring Harbor Laboratory, New York. 
Schoch CL, Seifert KA, Huhndorf S, Robert V, Spouge JL, Levesque CA, Chen W, Fungal Barcoding Consortium, 2012. Nuclear ribosomal internal transcribed spacer, (ITS) region as a universal DNA barcode marker for Fungi. Proceedings of the National Academy of Sciences USA 109: 6241-6246.

Takó M, Csernetics, A, 2005. Genotypic analysis of variability in Zygomycetes. A minireview. Acta Biologica Hungarica 56: 345-357.

Tamura K, Peterson D, Peterson N, Stecher G, 2011. MEGA5: molecular evolutionary genetics analysis using maximum likelihood, evolutionary distance, and maximum parsimony methods. Molecular Biology and Evolution 28: 2731-2739.

Tanabe Y, Saikawa M, Watanabe MM, Sugiyamac J, 2004. Molecular phylogeny of Zygomycota based on EF-1 $\alpha$ and RPB1 sequences: limitations and utility of alternative markers to rDNA. Molecular Phylogenetics and Evolution 30: 38-449.

Thaxter R, 1914. New or peculiar Zygomycetes. 3: Blakeslea, Dissophora, and Haplosporangium, nova genera. Botanical Gazette 58: 353-366.

Thompson JD, Higgins DG, Gibson TJ, 1994. CLUSTAL W: improving the sensitivity of progressive multiple sequence alignment through sequence weighting, positionspecific gap penalties and weight matrix choice. Nucleic Acids Research 22:4673-4680.

Vitale RG, de Hoog GS, Schwarz P, Dannaoui E, Deng S, Machouart M, Voigt K, van de Sande WW, et al., 2012. Antifungal susceptibility and phylogeny of opportunistic members of the order mucorales. Journal of Clinical Microbiology 50: 66-75.

Voigt K, Wöstemeyer J, 2001. Phylogeny and origin of 82 zygomycetes from all 54 genera of the Mucorales and Mortierellales based on combined analysis of actin and translation elongation factor EF-1 $\alpha$ genes. Gene 270: 113-120.

Walther G, Pawlowska J, Alastruey-Izquierdo A, Wrzosek M, Rodríguez-Tudela JL, Dolatabadi S, Chakrabarti A, de Hoog GS, 2013. DNA barcoding in Mucorales: an inventory of biodiversity. Persoonia 30: 11-47. 
Weddle G, Gandy K, Bratcher D, Pahud B, Jackson MA, 2012. Apophysomyces trapeziformis infection associated with a tornado-related injury. Pediatric Infectious Disease Journal 31: 640-642.

Wetzel J, Burmester A, Kolbe M, Wöstemeyer J, 2012. The mating-related loci sexM and sexP of the zygomycetous fungus Mucor mucedo and their transcriptional regulation by trisporoid pheromones. Microbiology 158: 1016-1023.

White MM, James TY, O’Donnell K, Cafaro MJ, Tanabe Y, Sugiyama J, 2006. Phylogeny of the Zygomycota based on nuclear ribosomal sequence data. Mycologia 98: 872-884.

White TJ, Bruns T, Lee S, Taylor J, 1990. Amplification and direct sequencing of fungal ribosomal RNA genes for phylogenetics. In: Innis MA, Gelfand DH, Sninsky JJ, White TJ (eds) PCR Protocols: a Guide to Methods and Applications. San Diego Academic Press, San Diego, pp. 315-322.

Wickham H, 2009. ggplot2: elegant graphics for data analysis. Springer, New York.

Woo PC, Leung SY, To KK, Chan JF, Ngan AH, Cheng VC, Lau SK, Yuen KY, 2010. Internal transcribed spacer region sequence heterogeneity in Rhizopus microsporus: implications for molecular diagnosis in clinical microbiology laboratories. Journal of Clinical Microbiology 48: 208-214.

Yoshida K, Ootaki T, Ortega JKE, 1980. Spiral growth in the radially-expanding piloboloid mutants of Phycomyces blakesleeanus. Planta 149: 370-375.

Zycha H, Siepman R, Linnemann G, 1969. Mucorales. J. Cramer, Lehre.

\section{Data Accessibility}

The accession numbers in Table S2 refer to DNA sequences available in EMBL. 


\section{Figure captions}

Fig. 1 Global distribution of P. blakesleeanus (stars) and P. nitens (circles). Isolation sites of new strains (filled symbols) and old strains (empty symbols). The Iberian Peninsula and the Canary Islands are enlarged in the boxes.

Fig. 2 The spores of Phycomyces. For strain identification see Table 1; empty symbols are used for P. blakesleeanus and filled symbols for P. nitens. (Above) Micrographs of spore samples from four representative strains; phase contrast (left) and DAPI nuclear stain (right). (Below left) Mean length (major axis) and mean eccentricity of the microscopic image of the spores from 42 strains. The eccentricity of each spore was calculated as $\sqrt{ }\left(1-b^{2} / a^{2}\right)$, where "a" and "b" are the major and minor axes. (Below right) Cumulative frequencies of the number of nuclei per spore in 18 strains.

Fig. 3 Growth of P. nitens at different temperatures. Dry mass after six-days' growth and radial colony expansion during the third day of growth. For strain identification see Table 1; empty circles are used for $P$. blakesleeanus and filled symbols for $P$. nitens.

Fig. 4 Tandem DNA repeat for rRNAs of P. blakesleeanus strain NRRL1555. Filled bars, sequences for the four rRNAs; empty bars, intergenic spacers (IGS) and internal transcribed spacers (ITS).

Fig. 5 Parsimony cladogram of the ITS/5.8S sequences of 93 strains of Phycomyces. The tree is drawn to scale with the number of nucleotide changes in each branch.

Fig. 6 Genetic relationships of 56 strains of P. blakesleeanus. NMDS distances between the strains according to a Jaccard matrix of the dissimilarity of 27 restriction-length polymorphisms. For strain identification see Table 1. Squares represent strains from Europe; circles, from North America; triangle, from Asia; and lozenges, unknown origin. Seven local populations isolated from the same biomass sample are color-marked: Florida, pink; South Carolina, red; Houston, Texas, blue; Dallas, Texas, yellow; Tennessee, green; Virginia, orange; Michigan, light green. 
Fig. 7 The sex allelomorphs of four Mucorales. Comparison of those of P. nitens S608 and S609 and B. trispora F986 and F921, obtained in this work, and those of P. blakesleeanus (Idnurm et al. 2008) and M. circinelloides (Lee et al. 2008). Filled bars, coding sequences of genes tptA, $r n h A$, sexP, and sexM. Empty bars, homologous non-coding sequences. Hatched bars, unique, sex- and species-specific sequences.

Fig. 8 Evolutionary relationships of seven Mucorales. Maximum-likelihood cladograms of sexM, sexP, $r n h A$, and ITS/5.8S sequences, with branch lengths proportional to the number of substitutions per site. Dotted lines represent branches with bootstrap values under 0.5. 
Table 1 Strains of Phycomyces used in this work.

\begin{tabular}{|c|c|c|c|c|c|c|c|}
\hline \multicolumn{2}{|c|}{ Strain $^{a}$} & Origin & Collector & Isolator, year & Sex & Ref. $^{b}$ & Comments \\
\hline \multicolumn{8}{|c|}{ Phycomyces blakesleeanus } \\
\hline 1 & C168 & Santa Cruz, CA, USA & & Burke, 1971 & $(+)$ & (1) & Thick sporangiophores \\
\hline \multirow[t]{2}{*}{2} & Carmichael666 & Alberta, Canada & & Carmichael, 1959 & $(-)$ & (1) & Dung of mouse \\
\hline & Carmichael667 & Alberta, Canada & & Carmichael, 1959 & $(-)$ & (1) & Dung of deer mice \\
\hline 3 & CBS142.22 & Utrecht, Holland & & Wassink, 1922 & $(-)$ & (1) & \\
\hline 4 & CBS189.27 & USA & & Blakeslee, 1927 & $(-)$ & (1) & \\
\hline 5 & CBS282.35 & Utrecht, Holland & & Wassink, 1922 & $(-)$ & (1) & \\
\hline 6 & G5 & Worcester, MA, USA & & Lougee, 1952 & $(+)$ & (1) & Over leaf \\
\hline 7 & $\mathrm{~K} 1$ & Germany & & & $(+)$ & (4) & \\
\hline \multirow[t]{2}{*}{8} & KACC46094 & South Korea & & & $(-)$ & (3) & From fermented soybean \\
\hline & KACC46095 & South Korea & & & $(-)$ & (3) & From fermented soybean \\
\hline 9 & $\mathrm{KC} 1$ & Charleston, SC, USA & M. Powell & Idnurm, 2010 & $(+)$ & & Vomit of dog \\
\hline 10 & $\mathrm{KC} 2$ & Charleston, SC, USA & M. Powell & Idnurm, 2010 & $(+)$ & & Vomit of dog \\
\hline 11 & $\mathrm{KC} 3$ & Charleston, SC, USA & M. Powell & Idnurm, 2010 & $(+)$ & & Vomit of dog \\
\hline 12 & $\mathrm{KC} 4$ & Charleston, SC, USA & M. Powell & Idnurm, 2010 & $(+)$ & & Vomit of dog \\
\hline 13 & $\mathrm{KC} 5$ & Charleston, SC, USA & M. Powell & Idnurm, 2010 & $(+)$ & & Vomit of dog \\
\hline 14 & KC6 & Charleston, SC, USA & M. Powell & Idnurm, 2010 & $(+)$ & & Vomit of dog \\
\hline 15 & $\mathrm{KC} 7$ & Houston, TX, USA & B.W. Wallace & Idnurm, 2010 & $(-)$ & & Organic material under oak tree \\
\hline 16 & $\mathrm{KC} 8$ & Houston, TX, USA & B.W. Wallace & Idnurm, 2010 & $(+)$ & & Organic material under oak tree \\
\hline 17 & KC9 & Houston, TX, USA & B.W. Wallace & Idnurm, 2010 & $(+)$ & & Organic material under oak tree \\
\hline 18 & $\mathrm{KC} 10$ & Houston, TX, USA & B.W. Wallace & Idnurm, 2011 & $(+)$ & & Organic material under oak tree \\
\hline 19 & $\mathrm{KC} 11$ & Houston, TX, USA & B.W. Wallace & Idnurm, 2011 & $(+)$ & & Organic material under oak tree \\
\hline 20 & $\mathrm{KC} 12$ & Houston, TX, USA & B.W. Wallace & Idnurm, 2011 & $(-)$ & & Organic material under oak tree \\
\hline 21 & KC13 & Dallas, TX, USA & E. Goodale & Idnurm, 2012 & $(-)$ & & Dung of cat \\
\hline 22 & $\mathrm{KC} 14$ & Dallas, TX, USA & E. Goodale & Idnurm, 2012 & $(-)$ & & Dung of cat \\
\hline 23 & $\mathrm{KC} 15$ & Dallas, TX, USA & E. Goodale & Idnurm, 2012 & $(-)$ & & Dung of cat \\
\hline 24 & $\mathrm{KC} 16$ & Fairfax, VA, USA & D. Johnston & Idnurm, 2012 & $(-)$ & & Dung of raccoon in attic \\
\hline 25 & $\mathrm{KC} 17$ & Fairfax, VA, USA & D. Johnston & Idnurm, 2012 & $(+)$ & & Dung of raccoon in attic \\
\hline 26 & $\mathrm{KC} 18$ & Fairfax, VA, USA & D. Johnston & Idnurm, 2012 & $(-)$ & & Dung of raccoon in attic \\
\hline
\end{tabular}




\begin{tabular}{|c|c|c|c|c|c|c|c|}
\hline 27 & $\mathrm{KC} 19$ & Fairfax, VA, USA & D. Johnston & Idnurm, 2012 & $(-)$ & & Dung of raccoon in attic \\
\hline 28 & $\mathrm{KC} 20$ & Fairfax, VA, USA & D. Johnston & Idnurm, 2012 & $(+)$ & & Dung of raccoon in attic \\
\hline 29 & $\mathrm{KC} 21$ & Fairfax, VA, USA & D. Johnston & Idnurm, 2012 & $(-)$ & & Dung of raccoon in attic \\
\hline 30 & $\mathrm{KC} 22$ & Howell, MI, USA & M. and S. Bowen & Idnurm, 2013 & $(+)$ & & Seeds in bird feeder \\
\hline 31 & $\mathrm{KC} 23$ & Howell, MI, USA & M. and S. Bowen & Idnurm, 2013 & $(+)$ & & Seeds in bird feeder \\
\hline 32 & $\mathrm{KC} 24$ & Nashville,TN, USA & C. McAlister & Idnurm, 2013 & $(+)$ & & Seeds \\
\hline 33 & $\mathrm{KC} 25$ & Nashville,TN, USA & C. McAlister & Idnurm, 2013 & $(-)$ & & Seeds \\
\hline 36 & $\mathrm{KC} 28$ & Sarasota, FL, USA & Wall family & Idnurm, 2013 & $(-)$ & & Vomit of cat \\
\hline 37 & KC29 & Sarasota, FL, USA & Wall family & Idnurm, 2013 & $(-)$ & & Vomit of cat \\
\hline 38 & KC30 & Sarasota, FL, USA & Wall family & Idnurm, 2013 & $(-)$ & & Vomit of cat \\
\hline 39 & NRRL1464 & & & & $(-)$ & $(1,2)$ & \\
\hline 40 & NRRL1465 & & & 1903 & $(+)$ & $(1,2)$ & Dung of rabbit \\
\hline 44 & NRRL2566 & Germany & & Zycha, 1935 & $(-)$ & $(1,2)$ & Piloboloides \\
\hline 45 & NRRL6737 & & & & $(-)$ & (1) & \\
\hline 46 & NRRL6740 & & & & $(-)$ & (1) & \\
\hline 47 & RSA499 & Peterborough, NH, USA & & Benjamin, 1956 & $(-)$ & (1) & Dung of rodent \\
\hline 48 & RSA531 & Claremont, CA, USA & & Benjamin, 1957 & $(-)$ & (1) & Dung of pack rat \\
\hline & RSA537 & Claremont, CA, USA & & Benjamin, 1957 & $(-)$ & (1) & Dung of mouse. \\
\hline 49 & RSA1739 & Montreal, Canada & & Lewis, 1961 & $(+)$ & (1) & Dung of chipmunk \\
\hline 50 & S271 & British Columbia, Canada & & Bandoni & $(+)$ & & Dung of cat \\
\hline 51 & UBC1 & British Columbia, Canada & & Bandoni, 1970s & $(+)$ & (1) & Nanus \\
\hline 52 & UBC21 & & & & $(+)$ & (1) & \\
\hline
\end{tabular}


Phycomyces nitens

57 Anastasiou538 Claremont, CA, USA

58 ATCC16327 Japan

59 CBS149.24 Germany

60 ICMP10093 Auckland, New Zealand

61 ICMP16924 Christchurch, New Zealand

62 IMI051077 Avon, England

63 Indoh1521 Gunma, Japan

$64 \mathrm{KC} 31$

$65 \mathrm{KC} 32$

$66 \mathrm{KC} 33$

67 NRRL2444

68 NRRL2678

69 NRRLA7595

70 S256

71 S257

$72 \quad \mathrm{~S} 270$

$73 \mathrm{~S} 465$

$74 \mathrm{~S} 466$

$75 \quad \mathrm{~S} 605$

76 S606

$77 \quad$ S607

$78 \quad \mathrm{~S} 608$

79 S609

$80 \quad \mathrm{~S} 642$

$81 \mathrm{~S} 643$

82 S644

$83 \quad \mathrm{~S} 645$

84 S646

$85 \quad \mathrm{~S} 651$

$86 \mathrm{~S} 653$

$87 \quad$ S654

\section{Howell, MI, USA}

Howell, MI, USA

San Jose, CA, USA

Surrey, England

Chiba, Japan

Blue Rapids, KA, USA

La Laguna, Tenerife, Spain

La Laguna, Tenerife, Spain

British Columbia, Canada

Exeter, England

Exeter, England

Aracena, Huelva, Spain

Cortes, Málaga, Spain

Jerez, Cádiz, Spain

Jerez, Cádiz, Spain

Jerez, Cádiz, Spain

El Paso, La Palma, Spain

Hermigua, Gomera, Spain

Hermigua, Gomera, Spain

Navia, Asturias, Spain

Los Barrios, Cádiz, Spain

El Garrobo, Sevilla, Spain

Ardales, Málaga, Spain

Ardales, Málaga, Spain
Benjamin, 1960

Indoh

Burgeff, 1924

McKenzie

Cooper, 2007

Parry, 1952

Takasaki, 1963

Idnurm, 2013

Idnurm, 2013

Idnurm, 2013

Martin

C.T. Rogerson

Cerdá, 1978

Cerdá, 1978

Bandoni

Webster

Webster

Flores, 1999

Cerdá Olmedo, 2003

J. Ramos Guelfo

Camino, 2003

J. Ramos Guelfo

Camino, 2003

Camino, 2003

Camino, 2003

E. Cerdá Olmedo

E. Cerdá Olmedo

E. Cerdá Olmedo

E. Rubio Domínguez

E. Cerdá Olmedo

J. Ramos Guelfo

Camino, 2007

Camino, 2007

Camino, 2007

Camino, 2008

Camino, 2010

Jurado, 2011

Domínguez, 2011
(+) (1) Dung of mouse

$(-) \quad$ (1) Dung of pig

(+) (2) P. theobromatus Burgeff

(+) Carpet

$(-) \quad$ Dung in wetlands

(+) $(1,2) \quad$ Front coconut meal

$(-) \quad$ (1) Dung of pig

(+) Seeds in bird feeder

$(+) \quad$ Seeds in bird feeder

$(-)$

(1)

(+) (2) Dung in gypsum mine

(+) Dung

(+) Dung

(+) Dung of cat

$(-)$

$(-)$

$(-)$

Dung of rabbit

Dung of rabbit

Mammal dung

Dung of dog

Mammal dung in Higueral cave

Mammal dung in Higueral cave

Mammal dung in Higueral cave

Dung of rabbit

Organic matter

Organic matter

Dung of dog

Dung of rat

Dung of mammal

Organic matter in Ardales cave

Dung of mammal in Ardales cave 


\begin{tabular}{|c|c|c|c|c|c|c|}
\hline 88 & S655 & Ardales, Málaga, Spain & & Domínguez, 2011 & $(-)$ & Dung of mammal in Ardales cave \\
\hline 89 & S656 & Ardales, Málaga, Spain & & Domínguez, 2011 & $(-)$ & Dung of mammal in Ardales cave \\
\hline 90 & S657 & Aracena, Huelva, Spain & & Domínguez, 2011 & $(-)$ & Organic matter in Aracena cave \\
\hline 91 & S658 & Cortegana, Huelva, Spain & M. Alvarado Cordobés & Camino, 2011 & $(-)$ & Dung of mammal \\
\hline 92 & S659 & Cazalla, Sevilla, Spain & M. Alvarado Cordobés & Camino, 2012 & $(-)$ & Dung of mammal \\
\hline 93 & S660 & C. las Guardas, Sevilla, Spain & I. López Calderón & Camino, 2012 & $(-)$ & Dung of cat \\
\hline 94 & UBC39 & British Columbia, Canada & & Spencer, 1963 & $(-)$ & Trash of basement \\
\hline 95 & UBC67 & & & & $(+)$ & \\
\hline 96 & UBC149 & British Columbia, Canada & & Reid, 1972 & $(-)$ & Dung of cat \\
\hline
\end{tabular}

a The number on the left is the abbreviation used in the Figures; the three unnumbered strains are believed to be identical to the ones preceding them. Strain names refer to the laboratory where they were isolated or the collection where they are deposited: C, Laboratory of M. Delbrïck, California Institute of Technology, Pasadena, CA, USA; S, Laboratory of E. Cerdá-Olmedo, Departamento de Genética, Facultad de Biología, Universidad de Sevilla, Spain; KC, A. Idnurm, now at University of Melbourne, Australia; CBS, Centraalbureau voor Schimmelcultures, Ütrecht, Netherlands; G, Indoh, Anastasiou, and Carmichael: University of Saskatchewan, Saskatoon, Canada; NRRL, Northern Regional Research Laboratory, USDA, Peoria, IL, USA; RSA, R.K. Benjamin, Claremont, CA, USA; K, B. Furch, Universität Kiel, Germany; UBC, R. J. Bandoni, University of British Columbia, Canada; KACC, Korean Agricultural Culture Collection, Swon, South Korea; ATCC, American Type Culture Collection, USA; ICMP, International Collection of Microorganisms from Plants, New Zealand; IMI, International Mycological Institute, Kew, UK.

b (1) (Ootaki and Miyazaki 1993) (2) (Benjamin and Hesseltine 1959) (3) (Hong et al. 2012) (4) (Van Laere 1983) 


\section{Figure(s)}

Figure 1

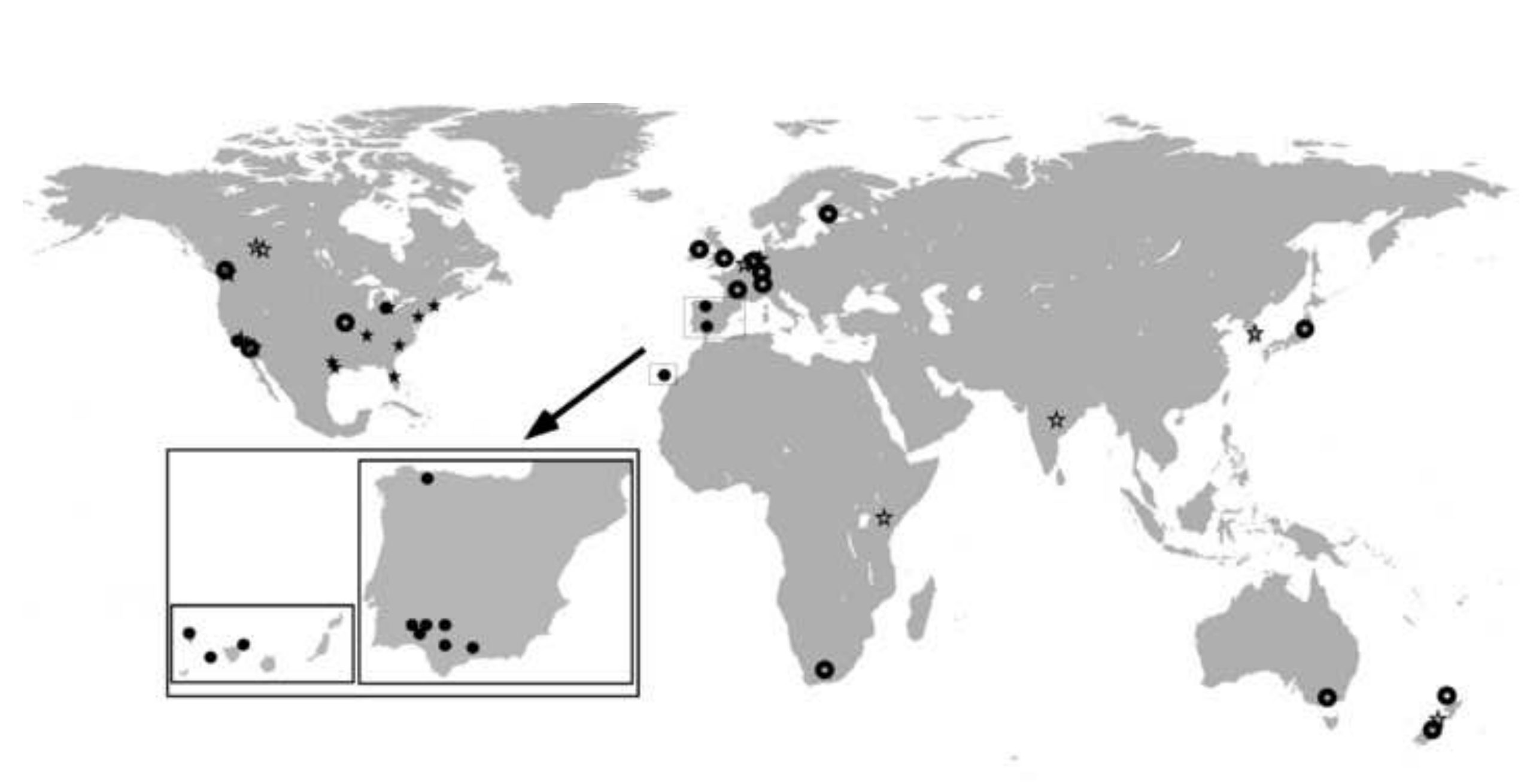

Figure 1

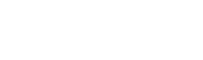

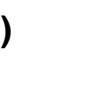
.
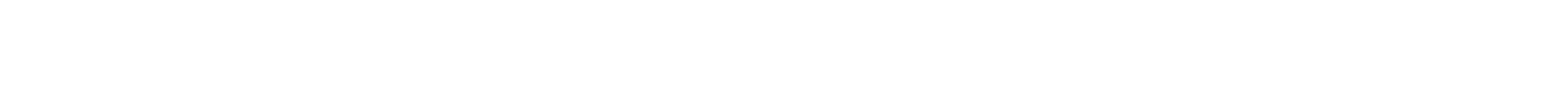

.

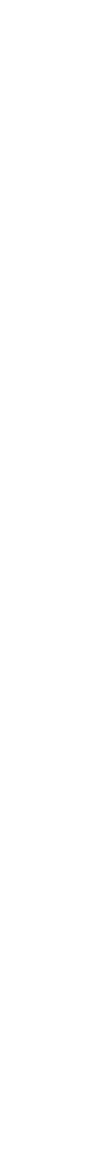



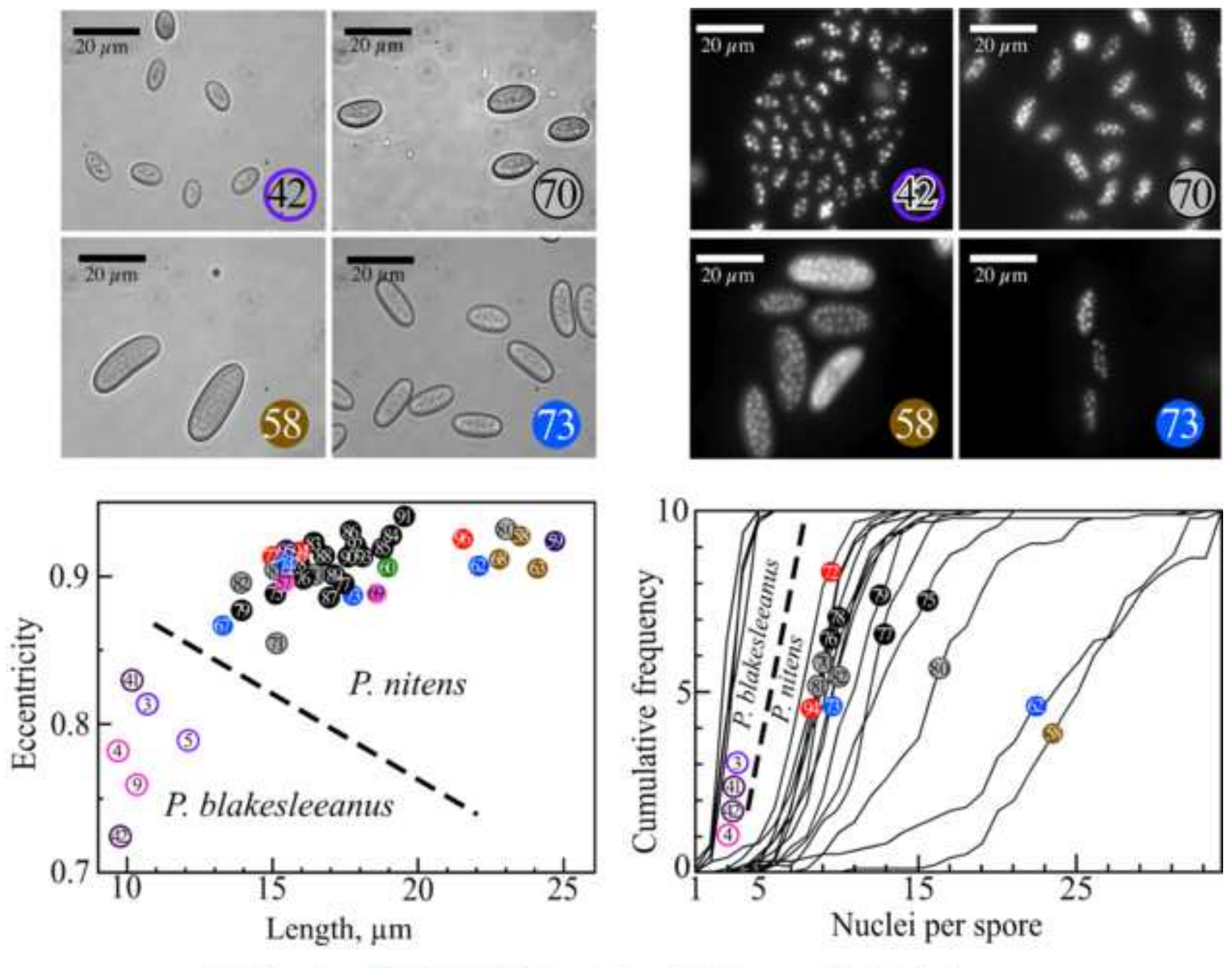

Canada USA Australia Japan England

Iberian Peninsula $\bigcirc$ Canary Islands Germany $\bigcirc$ Holland 


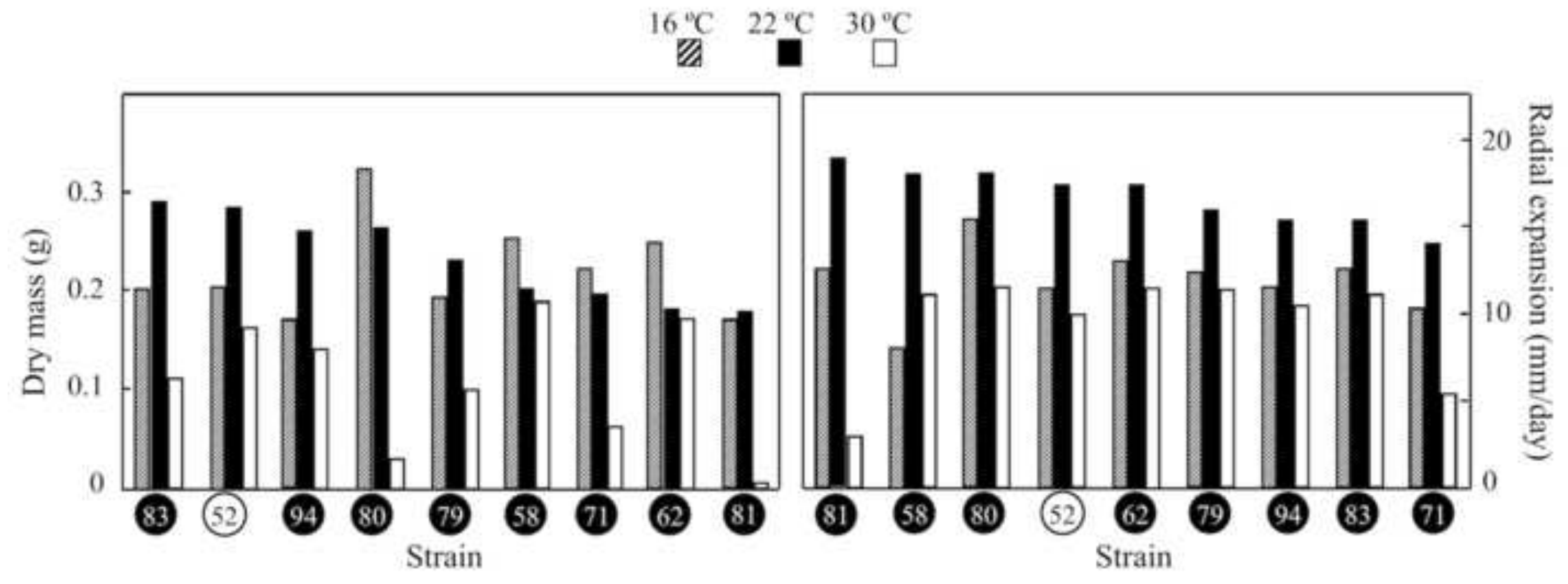


Figure 4

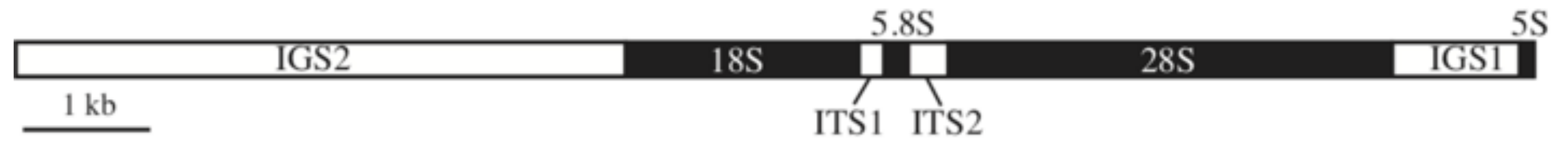


Phycomyces nitens

Phycomyces blakesleeanus

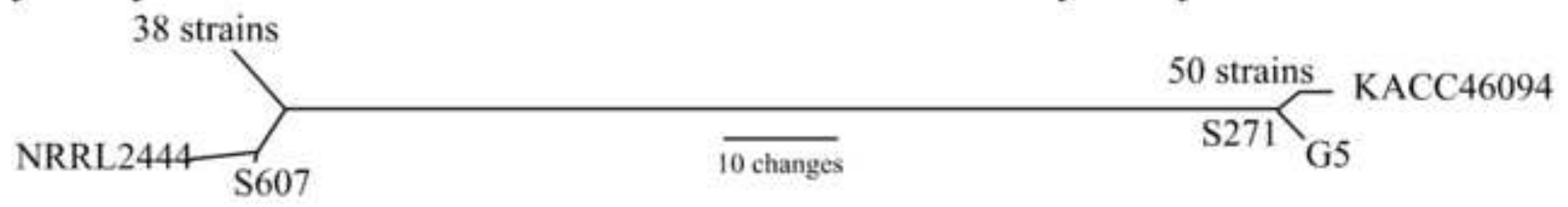




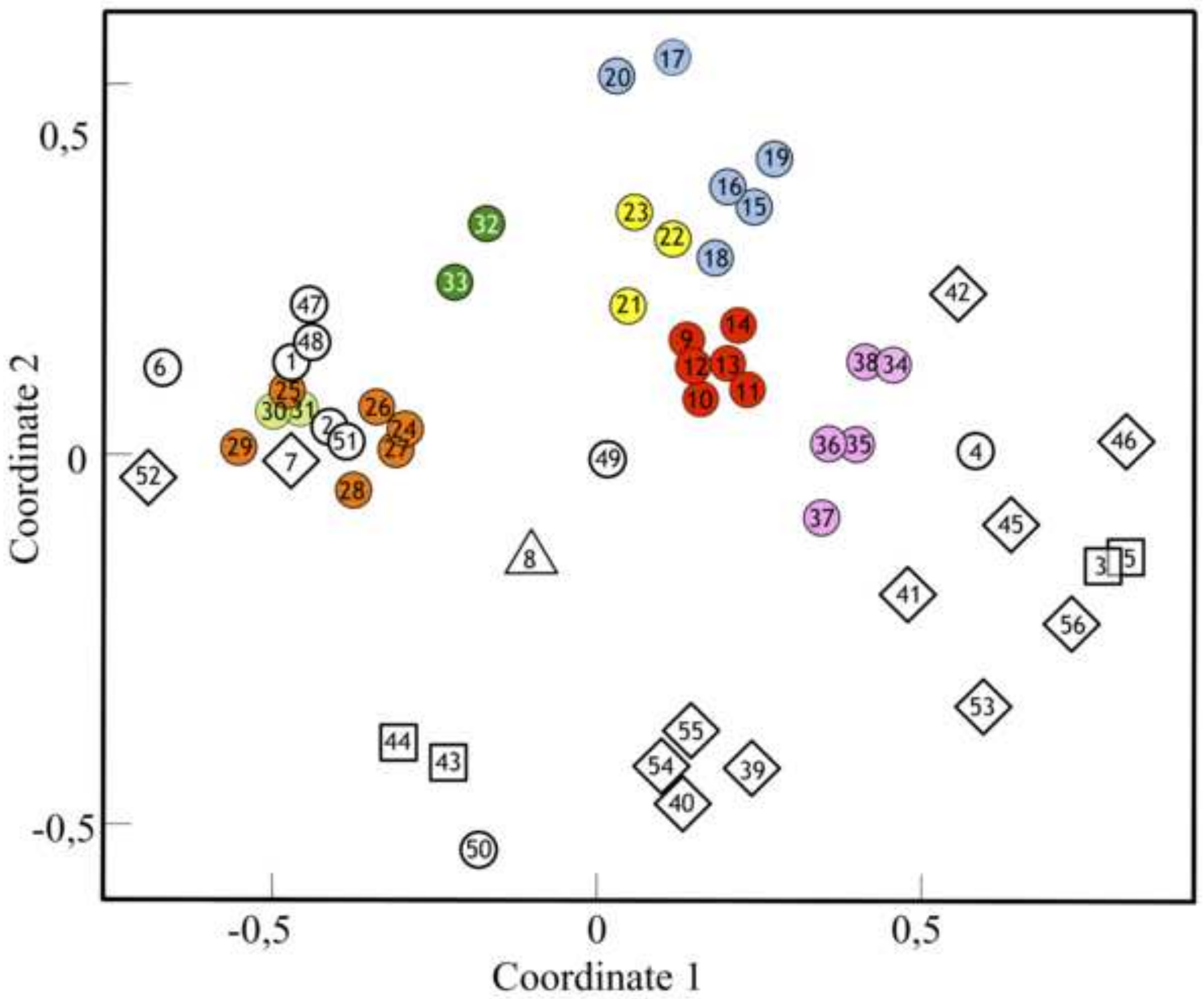


P. nitens

$3 \quad$ sexP

$r n h A$

$\rightarrow$

$$
3 \quad \text { NIIIIIIV } \stackrel{\operatorname{sex} M}{\rightarrow} \text { III }
$$

rnhA

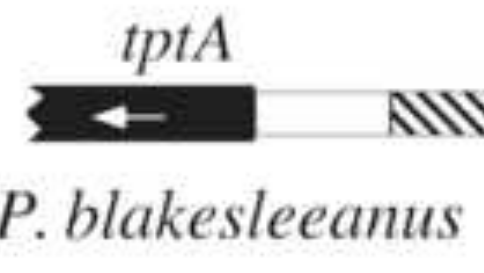

P. blakesleeanus

$$
\operatorname{sex} P
$$$$
\leftarrow
$$

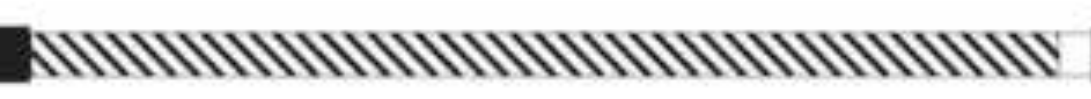

\begin{tabular}{|c|c|c|}
\hline$t p t A$ & $\operatorname{sex} M$ & $\operatorname{rnh} A$ \\
\hline
\end{tabular}

$r n h A$

B. trispora $\quad$ circinelloides




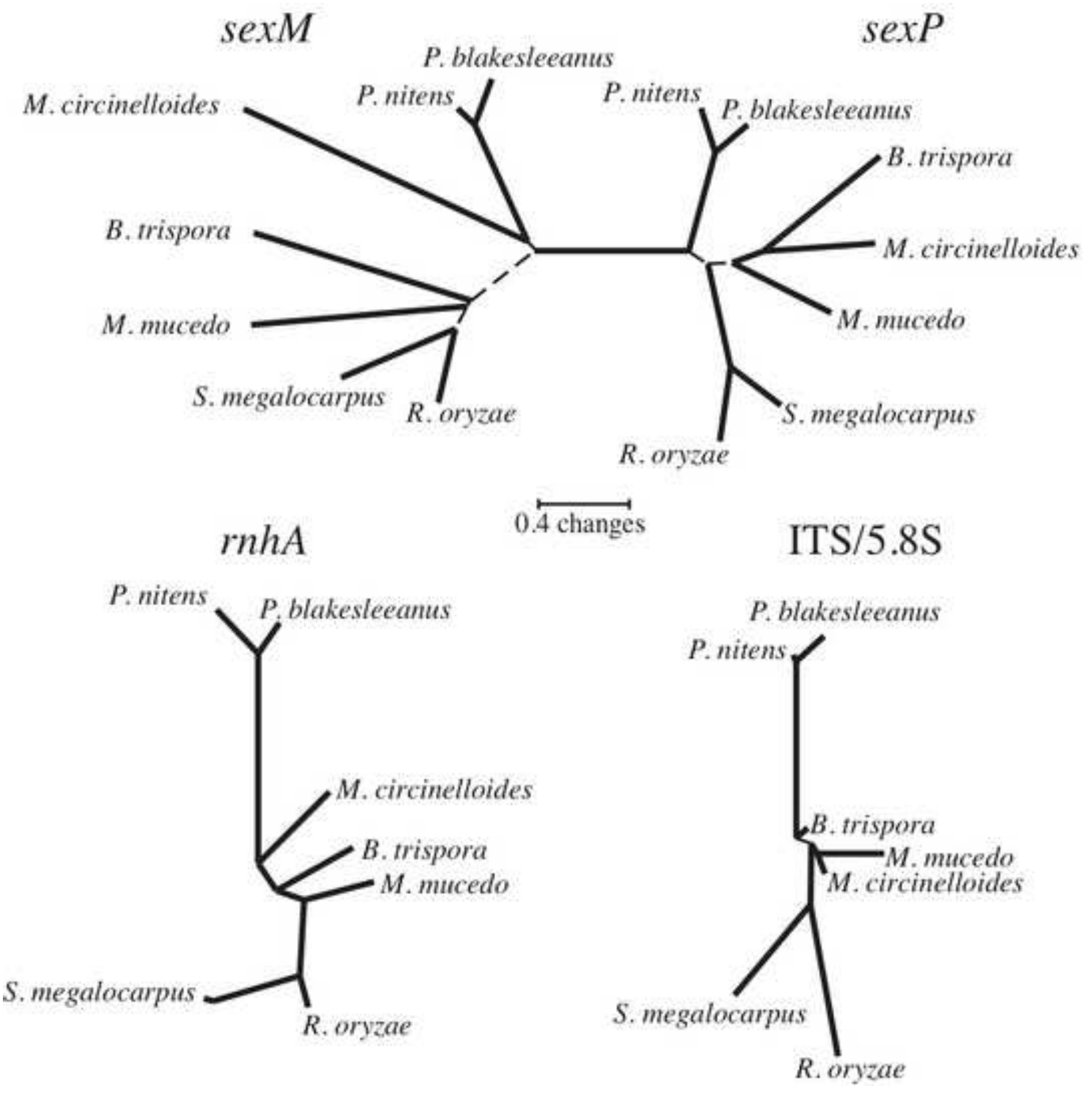

